Fifth International Conference on Sustainable Construction Materials and

Technologies. http://www.claisse.info/Proceedings.htm

\title{
PROPERTIES OF COMPOSITE PREPARED BY STABILIZING SOIL WITH MOLTEN POST- CONSUMER PLASTIC WASTE BOTTLES
}

\author{
Pranshoo Solanki ${ }^{1}$ and Samikaran Bhattarai ${ }^{2}$ \\ ${ }^{1}$ Associate Professor, Construction Management Program, Department of Technology, \\ College of Applied Science and Technology, Illinois State University, Campus Box \\ 5100, Normal, IL 61790, USA, psolanki@ilstu.edu (Corresponding Author) \\ ${ }^{2}$ Graduate Assistant, Department of Technology, College of Applied Science and \\ Technology, Illinois State University, Campus Box 5100, Normal, IL 61790, USA
}

\begin{abstract}
This study focused on evaluating the properties of a composite developed by stabilizing soil with molten post-consumer polyethylene terephthalate (PET) plastic waste bottles. A total of five soil-plastic composite mixtures mixes were designed using different PET and soil content. Using the mix designs, cylindrical samples of soil-plastic composite were produced in mold by compacting a mixture containing molten PET and heated soil in accordance with proportions determined from mix design. Dry soilplastic composite specimens were tested for strength, moisture susceptibility and 3dimensional swell. The developed soil-plastic composite specimens produced higher compressive strength values as compared to control specimens containing up to $10 \%$ cement; 25\% PET content provided densest and strongest structure. Increase in PET content made soil-plastic composite specimens more moisture and swell resistant. Overall, findings from this study indicate that soil-plastic composites could be potentially used for construction applications and offer an effective technique for diverting a large amount of PET plastic from landfills and incinerators.
\end{abstract}

Keywords: polyethylene terephthalate, composite, stabilization, plastic, recycling

\section{INTRODUCTION}

Plastics are important part of our lives. Plastics are used in the entire world for packaging, toys, electronic products, shopping bags, fluid bottles, automotive industry and construction material. Approximately 32.5 million tons of plastic waste is generated annually in the United States (US), which is around $12.8 \%$ of entire municipal solid waste (EPA, 2015). Subramanian (2000) reported the amount of different types of plastics in the waste stream (Table 1). Approximately $9.2 \%$ of plastic waste includes Polyethylene Terephthalate (PET). Beverages, food, and other consumer products are delivered in bottles or packages made from PET. In 2015, approximately 5,971 million pounds of PET bottles were sold into the marketplace in 
the US (NAPCOR, 2016). PET bottles have taken the place of glass bottles as storing container of beverages due to its lightweight and easiness of handling and storage (Frigione, 2010).

Siddique et al. (2008) reported that the amount of plastic consumed and wasted in UK was 4.7 and 3.0 million tons, respectively, in Year 2001. On the other hand, the amount of plastic consumed and wasted in the US was 26.7 and 11.0 million ton, respectively, in Year 2003. According to Siddique et al. (2008), only 7\% of total post-consumer plastic waste is recycled whilst the remaining $80 \%$ is sent to be landfilled and $8 \%$ to be incinerated. The major problem that this level of waste production generates initially entail storage and elimination. In the case of PET, a thermoplastic, regeneration is feasible through recycling. Therefore, the post-consumer PET waste is sorted, crushed, pressed into bales and offered for sale to recycling companies (Frigione, 2010). Recycling companies further treat the post-consumer PET waste by shredding the material into small flakes which are used as raw material for a range of products. However, a vast amount of waste PET still remains un-used as it is one of the most abundant plastics in solid urban waste (Mello et al., 2009; Frigione, 2010). This results in the accumulation of plastic wastes and causes serious environmental problems due to littering and illegal landfilling or incineration. Consequently, the aim of this study was to evaluate the properties of a composite developed by stabilizing soil with molten post-consumer PET plastic waste bottles.

Table 1: Types and amount of plastics in municipal solid waste in the USA (Subramanian, 2000)

\begin{tabular}{|c|c|c|}
\hline Type of plastic waste & $\begin{array}{l}\text { Amount in } \\
1000 \text { tons }\end{array}$ & $\begin{array}{l}\text { Percent of total } \\
\text { plastic waste }\end{array}$ \\
\hline $\begin{array}{l}\text { High density polyethylene } \\
\text { (HDPE) }\end{array}$ & 4120 & 22.2 \\
\hline $\begin{array}{l}\text { Low density polyethylene } \\
\text { (LDPE) }\end{array}$ & 5010 & 27.0 \\
\hline $\begin{array}{l}\text { Polyethylene terephthalate } \\
\text { (PET) }\end{array}$ & 1700 & 9.2 \\
\hline Polypropylene (PP) & 2580 & 13.9 \\
\hline Polystyrene (PS) & 1990 & 10.7 \\
\hline Other plastics & 3130 & 16.9 \\
\hline
\end{tabular}

A large number of studies were conducted to study the use of various forms of thermoplastics (e.g., PET, High Density Polyethylene (HDPE), Polypropylene (PP)) in construction materials. A review on the use of plastic waste in concrete is available in Siddique et al. (2008), Saikia and Brito (2012) and Sharma and Bansal (2016). Overall, researchers recycled post-consumer plastics in construction materials in two ways: (1) plastic flakes/pellets/fibers as particle replacement or filler; and (2) molten plastic as a binder for producing new composites. However, no study to the authors' knowledge used molten plastic for stabilizing soil. Consequently, an attempt was made to develop 
a novel form of soil-plastic composite which can be used for construction applications. Utilization of post-consumer PET in construction will provide new market potential and greater likelihood for recycling by consuming the bulk of PET waste bottles and reduce the amount of waste entering landfills.

\section{METHODOLOGY AND EXPERIMENTAL DESIGN}

\section{Material Types and Sources}

The soil used in this study was collected from Portico Homes LLC residential construction site located in Normal, Illinois. Air dried soil was tested for sieve analysis and Atterberg limits in accordance with ASTM D 422 and ASTM D 4318, respectively. The test results showed soil with percent passing \#200 of $15 \%$, liquid limit of $20 \%$ and plasticity index of $15 \%$. Type 1 Portland cement was used for making control samples. The post-consumer PET bottles were collected from Illinois State University (ISU) recycling facility and donated by students/faculty at ISU. These bottles were shredded into flakes by using Nelmor Grinder/Granulator Model No. G1012P1 at Midwest Fiber Recycling, Normal, IL.

\section{Specimen Preparation}

A total of one control using $10 \%$ cement and five soil-plastic mixtures were prepared in this study. A summary of different mixtures along with different percentages of PET and soil used is presented in Table 2.

Table 2. A Summary of Soil-Plastic Composite Mixtures Developed in this Study

\begin{tabular}{|c|c|c|c|c|}
\hline Mix\# & $\begin{array}{c}\text { Sample } \\
\text { Label }\end{array}$ & PET (\%) & Soil (\%) & $\begin{array}{c}\text { Cement } \\
(\%)\end{array}$ \\
\hline Control & PC10 S90 & 0 & 90 & 10 \\
\hline 1 & P20 S80 & 20 & 80 & 0 \\
\hline 2 & P25 S75 & 25 & 75 & 0 \\
\hline 3 & P30 S70 & 30 & 70 & 0 \\
\hline 4 & P45 S55 & 45 & 55 & 0 \\
\hline 5 & P50 S50 & 50 & 50 & 0 \\
\hline
\end{tabular}

Five soil-plastic mixtures were prepared by using five PET content $(20 \%, 25 \%, 30 \%$, $45 \%$, and $50 \%$ ) and dry soil. Following is a brief procedure which was used for soilplastic mixture specimen preparation.

Step 1 - The required amount of dry PET waste bottle flakes and soil were weighed and mixed in a stainless steel bowl (Figs. $1 \mathrm{a}-\mathrm{b}$ ). 

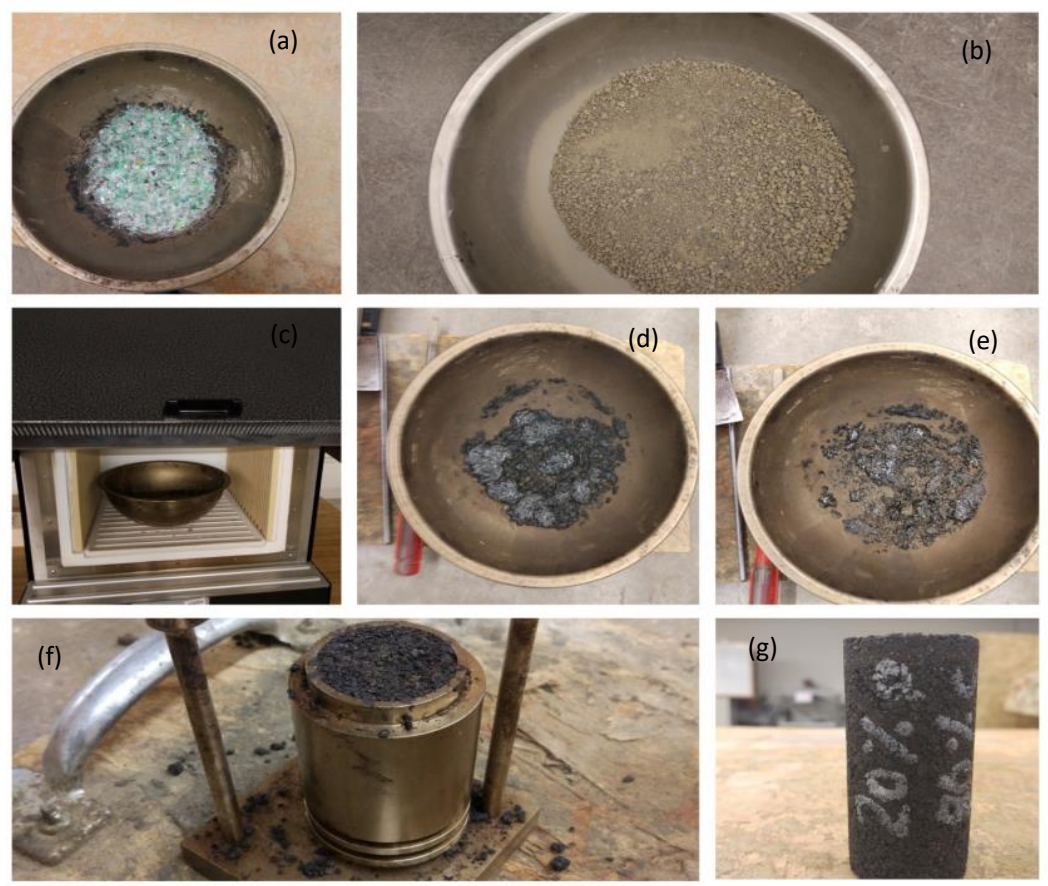

Figure 1. PSC sample preparation steps (a-g).

Step 2 - The stainless steel bowl containing the mixture was kept inside a preheated Ney Vulcan D-1750 oven at approximately $335 \pm 10^{\circ} \mathrm{C}$ for 15 minutes as shown in Fig. 1c. After 15 minutes the mixture was taken out from the oven and stirred using a stainless steel spoon (Fig. 1d). This stirred mixture was placed back in the oven and stirred again after another 10 minutes. This procedure was repeated three times until a homogenous mixture was obtained (Fig. 1e).

Step 3 - PET flakes-soil mix obtained from Step 2 was poured in a pre-heated Harvard miniature mold (diameter $=1.263 \mathrm{inch}$, height $=2.816 \mathrm{inch}$ ) and compacted using a steel rod in accordance with ASTM C 192 guidelines at room temperature (Fig. 1f). The final compacted mixture was allowed to cool down at room temperature for 24 hours. After 24 hours the compacted sample was extracted from the mold and labeled using a tag (Fig. 1g).

\section{Laboratory Tests}

Dry cylindrical samples of soil-plastic composite were tested for compressive strength, moisture susceptibility and 3-D (three-dimensional) swell tests. A brief description of each test is discussed in subsequent paragraphs.

Compressive Strength Tests: Compressive strength tests were conducted on the compacted control and soil-plastic composite specimens in a compression testing machine. A total of two replicates were prepared for each combination and then tested for compressive strength by loading specimens in a displacement control mode at a strain rate of $1 \%$ per min. 
Moisture Susceptibility Test: The moisture susceptibility of the compacted PSC samples was evaluated by moisture conditioning of the dry Harvard miniature specimens in water for 5 hours. This was achieved by immersing each specimen in an individual $250 \mathrm{ml}$ glass beakers filled with approximately $200 \mathrm{ml}$ of De-Ionized (DI) water. After 5 hours of immersion, the specimens were weighed to determine the percent water absorption. Then, the specimens were tested for UCS by loading them in a displacement control mode at a strain rate of $1 \%$ per minute. This test was successfully used by Khalife et al. (2012) for evaluating durability of cementitiously stabilized soil samples.

3-D Swell Test: To investigate the swelling potential of specimens, a three-dimensional (3-D) swell test was conducted in accordance with a procedure described by Solanki and Zaman (2010). The 3-D swell values were measured by determining the height to the nearest $0.025 \mathrm{~mm}\left(0.001 \mathrm{in}\right.$.) in 3 places that are $120^{\circ}$ apart. The diameter was measured to the nearest $0.025 \mathrm{~mm}(0.001 \mathrm{in}$.) near the top, in the middle, and near the base of each sample. The three height and diameter measurements were averaged and the 3-D swell was reported by calculating change in volume of specimen before and after soaking in water for 5 hours.

\section{RESULTS}

\section{Compressive Strength and Density}

Both compressive strength and density results of control and soil-plastic composite specimens are presented in Figure 2. Compressive strength was found to increase with increase in PET content up to $25 \%$ beyond which strength started decreasing with increase in PET content. All soil-plastic composite specimens tested in this study provided strength greater than that of the control specimen. For example, the soilplastic specimen prepared by using 25\% PET content provided a strength of approximately $32,314 \mathrm{kPa}$ which is $1073 \%$ greater than strength of control specimen. Density results presented in Figure 1 indicate a trend similar to the strength of soilplastic composite specimens. Therefore, increase in strength up to 25\% PET could be attributed to the structure of specimens which becomes densest at 25\% PET content. Another explanation is that PET content beyond $25 \%$ was not utilized in binding soil and since PET is a softer and lighter material decrease in density and UCS values is expected. 


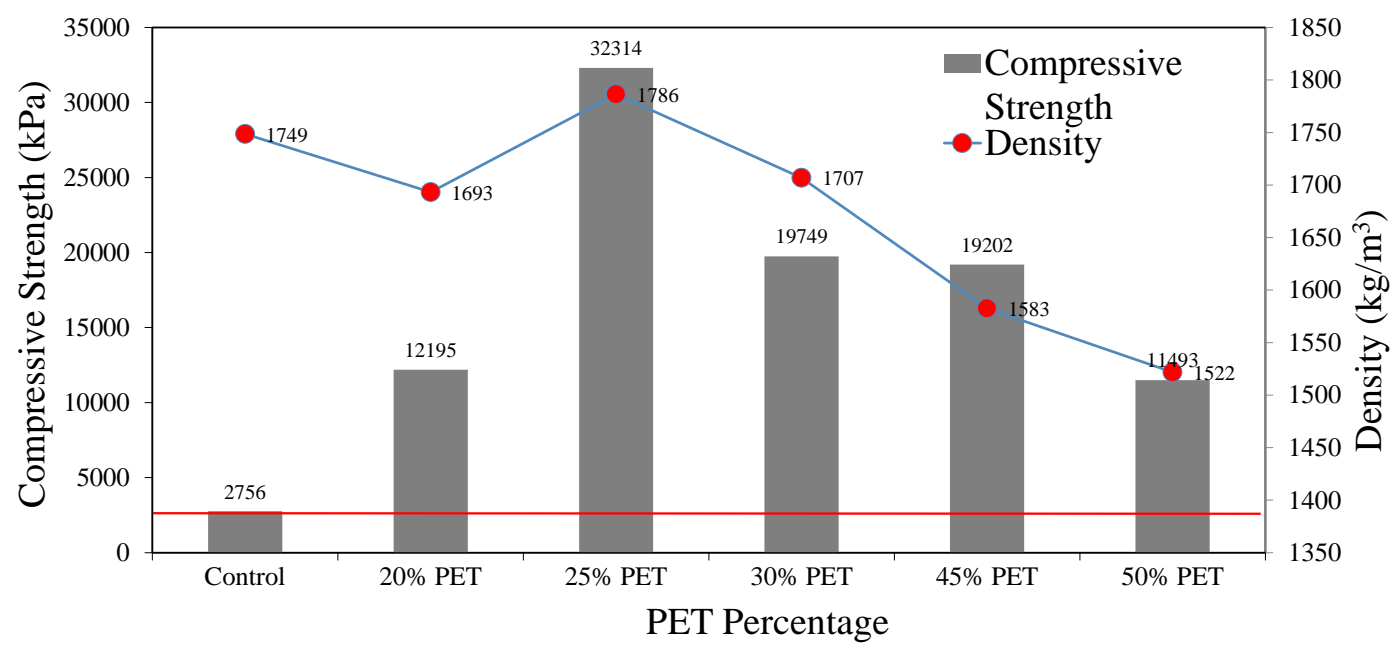

Figure 2. Compressive Strength and Density of Soil-Plastic Composite Specimens

\section{Dry and Soaked Strength}

Test results of dry (before 5-hr soaking), soaked (after 5-hr soaking) specimens and percent reduction in strength are presented in Figure 3. As expected, strength decreased after soaking specimens in water for 5 hours. The amount of percent reduction in strength is maximum for 20\% PET (approximately 98.2\%) containing specimen and it decreased with PET content. This is an indication that soil-plastic composite specimens became more moisture resistant with increase in PET content. This behavior is expected as PET is more moisture resistant compared to soil or cement. All soil-plastic specimens (except 20\% PET) showed soaked strength greater than dry strength of control specimen $(2756 \mathrm{kPa})$.

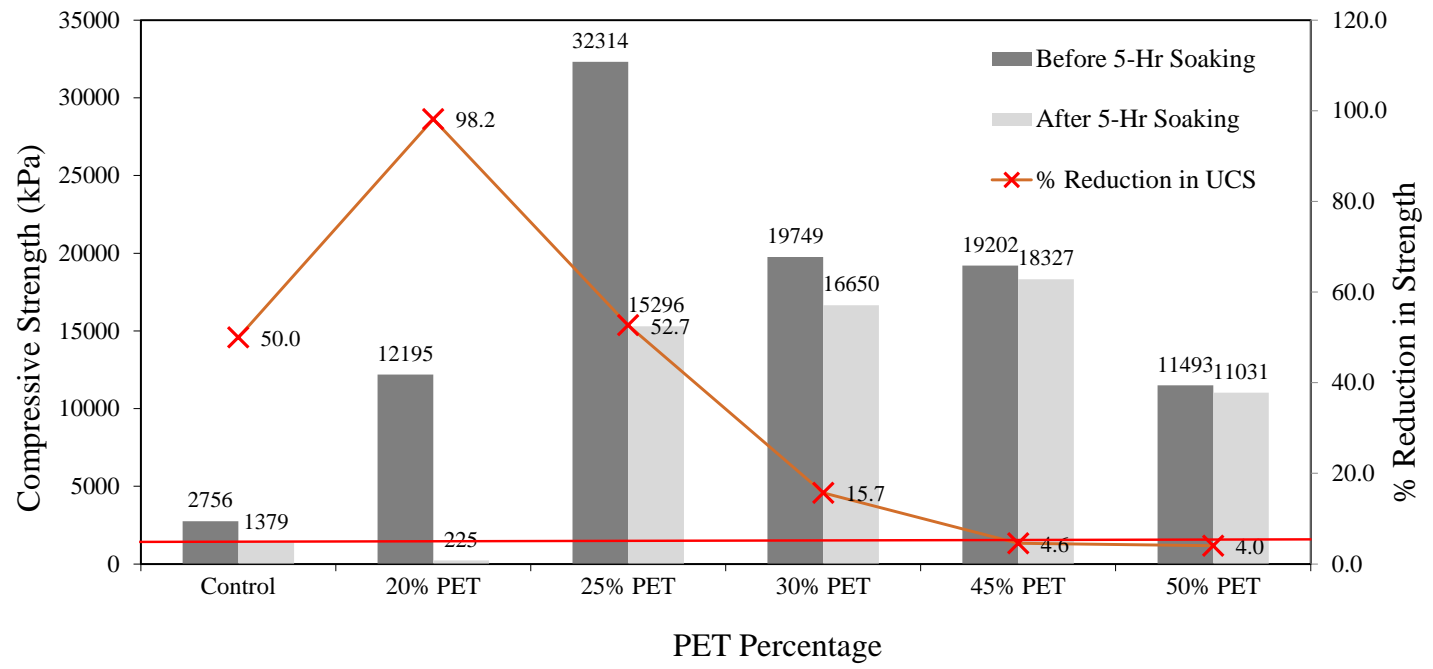

Figure 3. Compressive Strength of Control and Soil-Plastic Composite Specimens Before and After 5 Hours of Soaking 


\section{3-D Swell and Moisture Content}

Both 3-D swell and moisture content of 5 hours soaked specimens are presented in Figure 4. 3-D swell values were found to decrease with increase in PET content which is consistent with the trend of soaked strength as noted in previous section. Specimens containing $20 \%$ PET showed a maximum swell of $4.1 \%$ compared to $2.5 \%$ swell of control specimen. Moisture content was found to decrease with increase in PET content up to $25 \%$ beyond which increase in moisture content was noticed for 30\% PET content and then it plateaued. Amount of moisture content in specimen is directly related to density (see Figure 2) or porosity of specimen. As noted in Figure 2, 25\% PET specimen showed maximum density and thus least number of voids which can hold water resulting in least moisture content of $0.4 \%$.

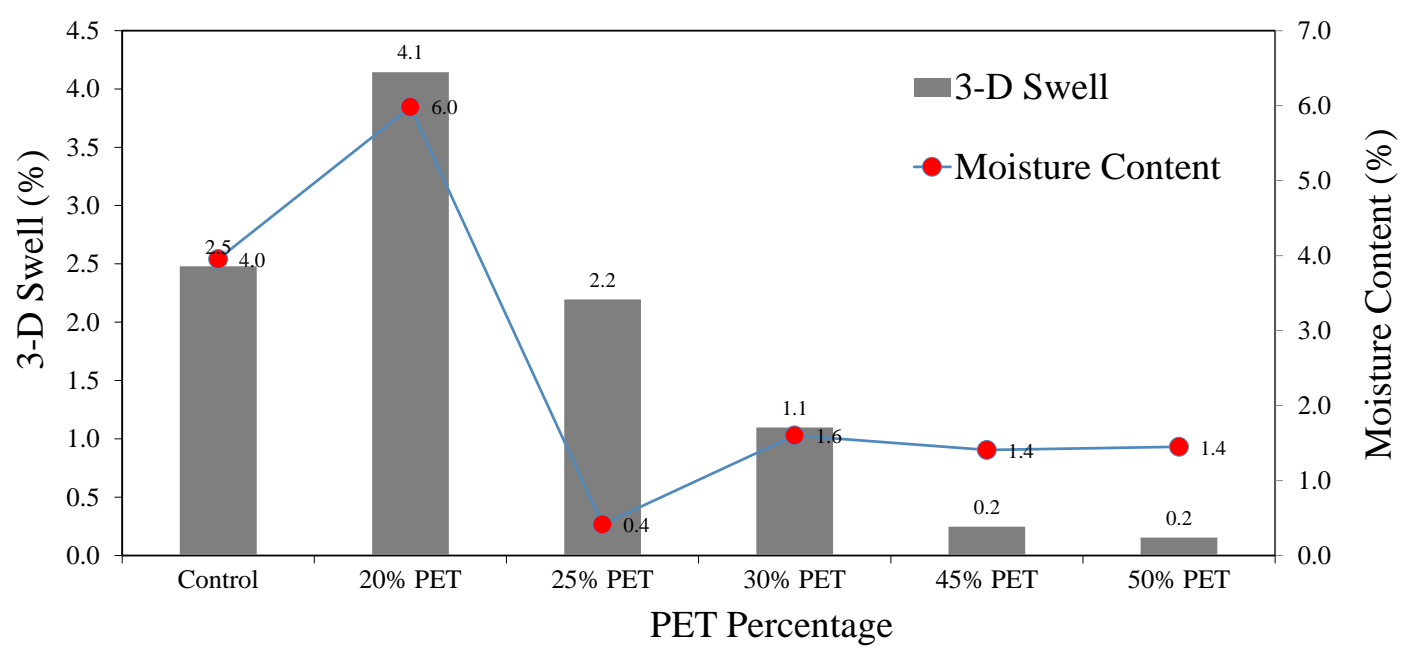

Figure 4. 3-D Swell and Moisture Content of Control and Soil-Plastic Composite Specimens Soaked in Water for 5 Hours

\section{CONCLUSIONS}

Based on the results presented in this study following conclusions could be drawn:

1) The developed soil-plastic composite mixtures produced higher compressive strength values as compared to control mixtures containing $10 \%$ cement. Additionally, 25\% PET content provided maximum strength value among all mixtures tested in this study; strength values were comparable to normal strength cement concrete. A consistent decrease in the compressive strength value was found beyond a PET content of $25 \%$.

2) Increase in PET content made soil-plastic specimens more moisture resistant. Soaked strength of 25\% PET containing specimen was found to be more than the strength provided by control prepared by using $10 \%$ cement.

3) PET content of $25 \%$ and above was found to decrease 3-D swell (less than 2\%) and more effective than $10 \%$ cement.

4) Both moisture content and density results showed that $25 \%$ PET containing soilplastic composite provides a structure which is densest and strongest among all the mixtures tested in this study. 
5) The developed soil-plastic composite containing 25\% PET content could be potentially used for applications where strength such as concrete as well as high level of moisture resistance is needed.

\section{ACKNOWLEDGMENTS}

This work was supported by the University Research Grant, College of Applied Science and Technology at Illinois State University (ISU). The material collection assistance provided by Prairie Material, Midwest Fiber Inc., Portico Homes LLC and ISU Office of Sustainability is gratefully acknowledged. Also, plastic bottles donated by ISU recycling facility and students/faculty for conducting this research is gratefully acknowledged.

\section{REFERENCES}

1. Batayneh, M., Marie, I., and Ibrahim, A. (2007). Use of Selected Waste Material in Concrete Mixes, Waste Management, Vol. 27, pp. 1870 - 1876.

2. Choi, Y. W., Moon, D. J., Chung, J. S., and Cho. S. K. (2005). Effects of Waste PET Bottles Aggregate on the Properties of Concrete, Cement and Concrete Research, Vol. 35, pp. $776-781$.

3. Choi, Y. W., Moon, D. J., Kim, Y. J. and Lachemi, M. (2009). Characteristics of Mortar and Concrete Containing Fine Aggregate Manufactured from Recycled Waste Polyethylene Terephthalate Bottles, Construction and Building Materials, Vol. 23, pp. $2829-2835$.

4. Environmental Protection Agency (EPA) (2015). Advancing Sustainable Materials Management: 2013 Fact Sheet, Assessing Trends in Material Generation, Recycling and Disposal in the United States, June 2015.

5. Frigione, M. (2010). Recycling of PET Bottles as Fine Aggregate in Concrete, Waste Management, Vol. 30, pp. $1101-1106$.

6. Ismail, Z. Z. and Al-Hashmi, E. A. (2008). Use of Waste Plastic in Concrete Mixture as Aggregate Replacement, Waste Management, Vol. 28, pp. 2041 - 2047.

7. Kashi, M., Malloy, R. and Swan, C. (2001). Development of Synthetic Lightweight Aggregate for Construction Material, Chelsea Center for Recycling and Economic Development Technical Research Program, July 2001.

8. Kashi, M., Malloy, R. and Swan, C. (2002). Fly Ash/Plastic Synthetic Aggregate for Construction Material, Chelsea Center for Recycling and Economic Development Technical Research Program, August 2002.

9. Khalife, R., Solanki, P., and Zaman, M. (2012), "Evaluation of Durability of Stabilized Clay Specimens Using Different Laboratory Procedures," ASTM Journal of Testing and Evaluation, 40(3), pp. 363-375.

10. Little, D. (2000). Evaluation of Structural Properties of Lime Stabilized Soils and Aggregates, Volume 3: Mixture Design and Testing Procedure for Lime Stabilized Soils, Report prepared for the National Lime Association, Arlington, VA.

11. Malloy, R., Kashi, M. and Swan, C. (2003). Fly Ash/Mixed Plastic Aggregate and Products Made Therefrom, U.S. Patent No. 6,669,773. 
12. Mello, D., Pezzin, S. H. and Amico, S. C. (2009). The Effect of Post-Consumer PET Particles on the Performance of Flexible Polyurethane Foams, Polymer Testing, Vol. 28, pp. $702-708$.

13. Meyers, III, Swartz, J. Kurczewski, N. and Kurczewski, M. (2006). Recyclable Composite Material Articles of Manufacture and Structures and Method of Using Composite Materials, U.S. Patent No. 6.984,670.

14. Naik, T. R., Singh, S. S., Huber, C. O., and Brodersen, B. S. (1996). Use of PostConsumer Waste Plastics in Cement-Based Composites, Cement and Concrete Research, Vol. 26, Issue 10, pp. 1489 - 1492.

15. National Association for PET Container Resources Member (NAPCOR) (2016). Postconsumer PET Container Recycling Activity in 2015, Report, Florence, KY.

16. Pelisser, F., Montedo, R.K.O., Gleize, J.P.P., Roman, R.H. (2012). Mechanical Properties of Recycled PET Fibers in Concrete, Materials Research, Vol. 15, No. 4, pp. $679-686$.

17. Rahmani, E., Dehestani, M., Beygi, M.H.A., Allahyari, H., and Nikbin, I.M. (2013). On the Mechanical Properties of Concrete Containing Waste PET Particles, Construction and Building Materials, Vol. 47, pp. 1302 - 1308.

18. Rai, B., Rushad, S.T., Bhavesh, K.R., and Duggal, S.K. (2012). Study of Waste Plastic Mix Concrete with Plasticizer, International Scholarly Research Notices Civil Engineering, Vol. 2012, pp. $1-5$.

19. Saikia, N. and Brito, J. D. (2012). Use of Plastic Waste as Aggregate in Cement Mortar and Concrete Preparation, Construction and Building Materials, Vol. 34, pp. $385-401$.

20. Sharma, R. and Bansal, P. P. (2016). Use of Different Forms of Waste Plastic in Concrete - A Review, Journal of Cleaner Production, Vol. 112, pp. 473 - 482.

21. Siddique, R., Khatib, J., and Kaur, I. (2008). Use of Recycled Plastic in Concrete: A Review, Waste Management, Vol. 28, pp. 1835 - 1852.

22. Solanki, P., and Zaman, M. M. (2010). Laboratory Performance Evaluation of Subgrade Soils Stabilized with Sulfate-Bearing Cementitious Additives, ASTM Journal of Testing and Evaluation, Vol. 38, No. 1, pp. 1-12.

23. Subramanian, M.P. (2000). Plastics recycling and waste management in the US, Resources Conservation Recycling, Vol. 28, pp. 253 - 263.

24. Yao, Z., Zhang, X., Ge, Z., Jin, Z., Han, J., and Pan, X. (2015). Mix Proportion Design and Mechanical Properties of Recycled PET Concrete, ASTM Journal of Testing and Evaluation, Vol. 43, No. 2, pp. $1-9$. 